Res Nondestr Eval (1994) 5:237

(C) 1994 Springer-Verlag New York Inc.

\title{
Erratum
}

\section{Silicon Sensors as Process Monitoring Devices}

P.A. Beck, B.A. Auld, and K.-S. Kim

Res Nondestr Eval 5:71-93 (1993)

Figures 19 and 20 were reversed. The figures and corresponding legends should have appeared as follows:

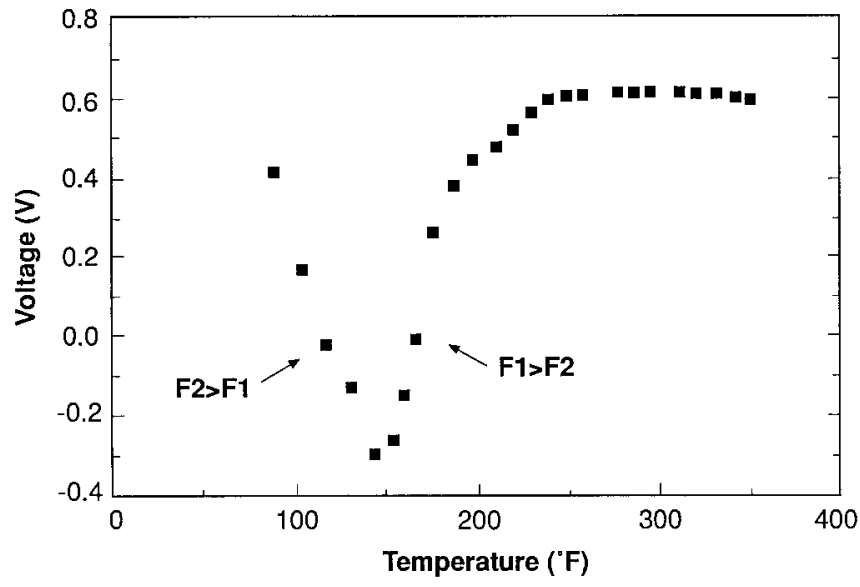

Fig. 19. Sensor output voltage (not externally balanced) during cure cycle in a thermosetting resin.

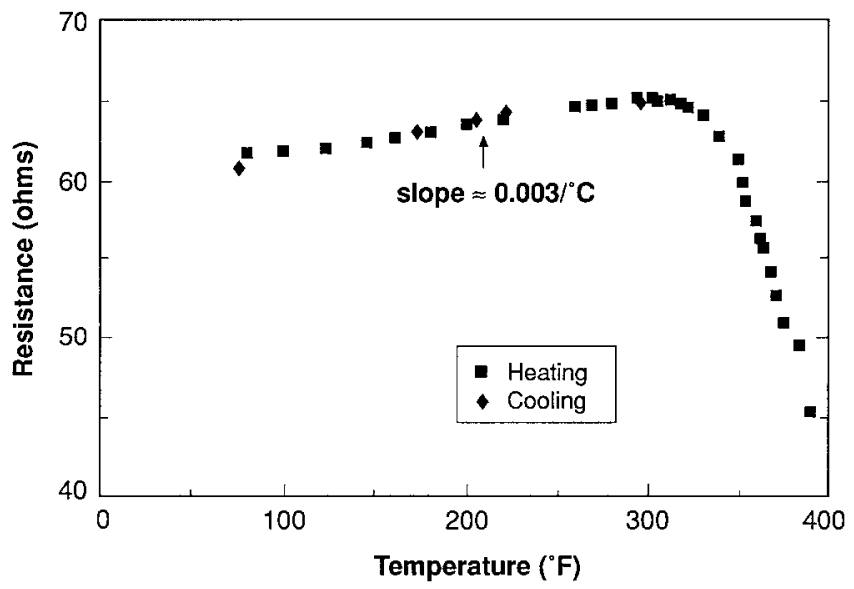

Fig. 20. Resistance as a function of temperature after final curing of the composite. 